\title{
Enzyme-Based Biosensors for Electrochemical Detection of Pesticides-A Mini Review
}

\author{
Keamou M. Soropogui, Ahmad T. Jameel, Wan Wardatul A. W. Salim \\ Biotechnology Engineering Department, Faculty of Engineering, International Islamic University Malaysia, Malaysia
}

\begin{tabular}{l}
\hline \hline Article Info \\
\hline Article history: \\
Received Apr 25, 2018 \\
Revised May 8, 2018 \\
Accepted May 11, 2018 \\
\hline
\end{tabular}

\section{Keyword:}

Biosensor

Electrochemical detection

Enzyme

Inhibition

Pesticides

\begin{abstract}
Despite their important contribution in increasing crops production, most pesticides are harmful to humans and living beings and can persist in the environment over long a long duration. Traditional chromatographic methods of analysis are expensive and cumbersome. Biosensor technology appears therefore as an efficient and economical alternative for fast detection of pesticides. The devices are portable, rapid, and highly sensitive. Other important features of the devices are their relatively high sensistivity and low response time. Enzymatic biosensors for pesticide detection rely either on the inhibition mechanism or on the catalytic activity of the immobilized enzyme toward a specific pesticide. Metal and carbon based nanomaterials are being widely used as immobilization support owing to novel characteristics such as biocompatibility and enhanced electron transfer ability for sensitive electrochemical detection, among others. This review focusses on the electrochemical detection of organophosphorus pesticides, delineating the limit of detection and response time of biosensors toward a wide range of organophosphorus pesticides.
\end{abstract}

Copyright $(0) 2018$ Institute of Advanced Engineering and Science. All rights reserved.

\section{Corresponding Author:}

Ahmad T. Jameel

Biotechnology Engineering Department, Faculty of Engineering,

International Islamic University Malaysia,

Gombak, 50728 Kuala Lumpur, Malaysia.

E-mail: atjameel@yahoo.com

\section{INTRODUCTION}

The continuous growth of world population has led to an increased use of plant growth regulators, including carbamates and organophosphorus pesticides (OPs) in modern agricultural practices in order to meet the global food demand. Organophosphorus alone represents around 38\% of pesticides used worldwide [1]. In addition, carbamates and OPs have some domestic applications, mainly to combat undesirable insects and garden pests. However, residues are not easily degradable and can persist in the environment over a long duration. Soil, air, water, food, and various other systems are therefore exposed to serious risk of contamination, becoming a serious threat to human health [2]. Severe exposure to pesticide can be highly toxic, mutagenic, carcinogenic, and tumorigenic for mammals [3], [4]. More importantly, the compounds have irreversible inhibitory effects on animal cholinesterase $(\mathrm{ChE})$, the enzymes responsible for the inactivation of choline-based esters (neurotransmitters) [1]. The inhibition of human acetylcholinesterase (AChE) leads to a constant increase of acetylcholine at the neuromuscular junction, initiating severe nerve dysfunction [5]. For this reason, environmental safety and food industries require strict control and quantification of pesticides. Considerable research has been undertaken over the past decades in order to control pesticides and to ensure public safety.

Classical methods of high-performance liquid chromatography (HPLC) and gas chromatography (GC) that used to quantify various types of contaminants (including pesticides) in environmental and food samples are expensive and time consuming, besides being tedious [4]. There was, therefore, a need of 
developing fast, accurate, low-cost, and portable analytical devices like biosensors for in-field detection of pesticides (carbamates, organophosphates, organochlorides, etc.) [6]. Immobilized enzymes for biosensing is one of the successful methods that have attracted the interest of many scientists. The techniques are based primarily on the inhibition and sensitivity of some enzymes, in particular acetylcholinesterase (AChE) and butyrylcholinesterase (BChE). Other types of enzymes used are alkaline and acid phosphatases, organophosphorus hydrolase, and tyrosinase [7]. Immobilization of plant esterases is a relatively new trend in enzyme-based biosensor design for simple and convenient detection of pesticides [1], [8], [9].

The high sensitivity of immobilized enzymes is an important factor in the development of a good biosensor. This allows the biosensor to detect one or several analytes in samples. However, enzymes used in biosensor technology for the detection of pesticides present less specificity toward a large number of pesticides, e.g., carbamates [2]. This review focuses on the recent techniques described in the literature using enzyme-based electrochemical biosensors in the quantification and analysis of pesticides. Parameters such as the limit of detection and the response time of these techniques are also presented and compared.

\section{ELECTROCHEMICAL ENZYME BIOSENSORS}

Electrochemical transducers have been successfully employed in enzyme biosensor technology for the quantification of numerous pesticides. The immobilized enzyme selectively reacts with the target analyte and results in an electrical signal that depends on the analyte concentration. The detection system in the majority of actual biosensors can be either amperometric (based on current measurement from the oxidation or reduction of $\mathrm{H} 2 \mathrm{O} 2$ or $\mathrm{O} 2$ ) or potentiometric (based on $\mathrm{pH}$ measurement due to acid formation by an enzyme-catalyzed reaction) [10]-[13]. Photometric biosensors using optical fibers and calorimetric biosensors that measure change in temperature are also being implemented for pesticide detection.

Electrochemical biosensors utilize electrodes that are essential in the detection process. The detection level of an electrochemical biosensor may depend on the dimension of the electrode surface, the nature of the material used, and the electrode modification technique. In contrast, the use of carbon- and metal-based nanomaterials and enzyme immobilization techniques is relevant in the process of electrochemical signal improvement. A potentiostat work station with a three-electrode system including a reference electrode, a working electrode, and an auxiliary or counter electrode is generally used in biosensor technology [11].

$\mathrm{Ag} / \mathrm{AgCl}$ is usually applied as the reference electrode. The electrode has the capacity of resisting the potential difference and has insignificant current. The quality of a reference electrode depends on its nonpolar ability and its capability to keep a constant potential during the passage of low current. The working electrode is the biological electrode, which consists in this case, an immobilized enzyme on an electrode made of such materials as glass carbon (e.g., glassy carbon electrodes), platinum, or gold. In an electrochemical system, all the processes of interest take place on the working electrode. The electrode may be used as cathode or anode, depending on the reaction that occurs. The auxiliary or counter electrode, made of inert material like platinum $(\mathrm{Pt})$ wire, does not interfere with the functioning of the working electrode [11].

The following steps describe the pesticide detection mechanism of an enzymatic biosensor. These biosensors can rely upon either the determination of the inhibition level of the immobilized enzyme (indirect approach) or the measurements of product resulting from the catalytic activity of the immobilized enzyme (direct approach) [4], [7], [12], [13].

\subsection{Enzyme Inhibition Biosensors}

Biosensing based on enzyme inhibition is a simple method that is mostly used for the detection of food and environmental pollutants. Analytes like pesticides or heavy metals (inhibitors) attach to the active site of the enzymes, and result in a considerable decrease of their catalytic properties. The advantage of these biosensors is that the enzymes are specifically inhibited by only a few inhibitors, therefore allowing high sensitivity and specificity in the detection of the target [13], [14]. However, despite their high sensitivity, these biosensors are indirect and their limits of detection (LODs) depend on factors like the nature of the electrode, the immobilization technique of the enzyme, and the contact time between the enzyme and the target analyte (e.g. pesticide) in aqueous medium [15], [16]. In addition, other inhibitors present in the assay sample may interfere in the inhibition process, leading to unexpected results. The resulting signal is inversely proportional to the concentration of the inhibitor present in the sample. In clear terms, the higher the inhibitor concentration, the weaker the signal.

In the absence of inhibitors (pesticide), the immobilized enzymes convert their specific substrates into products that can be electrochemically measured. However, when inhibitors are present, there will be a significant reduction of product, or even no product will be formed [17], [18]. Under the influence of applied voltage, the product is oxidized and the anodic oxidation current, whose strength depends on the amount of

IJEEI, Vol. 6, No. 2, June 2018: 161-171 
inhibitor in the sample and the duration of the exposure, is electrochemically measured [17]. The electrochemical response of the enzymatic biosensor can be determined using cyclic voltammetry (CV) or differential pulse voltammetry (DPV). The pesticide concentration can be determined by measuring the percentage of enzyme inhibition, before and after the exposure to the pesticide as shown in Equation 1 [19].

Inhibition $(\%)=100 \times(i p, c o n t r o l-i p, \exp ) / \mathrm{ip}$, control

where ip,exp and ip,control are the peak currents from the anodic oxidation of the products on the enzyme electrode with and without pesticide, respectively.

The electrode can consist of one, two, or three immobilized enzymes [16], [20]. In some cases, the binding of an inhibitor can be reversed as its concentration is decreased (reversible inhibition). Interestingly, biosensors based on this principle can be regenerated and reused. On the other hand, inhibition may be definitive as the inhibitor cannot be separated from the enzyme once the binding is completed (irreversible inhibition). Therefore, these biosensors are not reusable [15]. As stated in the introduction, AChE and BChE enzymes are commonly used in enzyme biosensor technology.

\subsubsection{Single Cholinesterase (ChE) Biosensor for Pesticide Detection}

These biosensors depend on the amperometric determination of OPs and carbamates [21]-[23]. In most cases, artificial substrates like acetylthiocholine (ATCh) and butyrylthiocholine (BTCh) are respectively used for the enzymes $\mathrm{AChE}$ and $\mathrm{BChE}$. However, some techniques utilize the natural substrates acethylcholine $(\mathrm{ACh})$ and butyrylcholine $(\mathrm{BCh})$. Typical reactions result in the conversion of $\mathrm{R}^{\text {'-choline or }}$ $\mathrm{R}^{\prime}$-thiocholine ( $\mathrm{R}$ ' is an acetyl or butyryl moiety) into choline or thiocholine and an acid (see Equations 2 and 3) [17]. When artificial substrates are used, the product $R^{\prime}$-thiocholine is electrochemically active and therefore detectable via anodic oxidation at $+0.6 \mathrm{~V}$ vs. $\mathrm{Ag} / \mathrm{AgCl}$, as shown in Figure 1 [24]. The catalytic reactions are shown in Equations 2 and 3 [20].

$$
\begin{aligned}
& \mathrm{ATCh}+\mathrm{H} 2 \mathrm{O} \rightarrow \underset{\text { thiocholine }+ \text { acetic acid }}{\mathrm{AChE}} \\
& \mathrm{BTCh}+\mathrm{H} 2 \mathrm{O} \rightarrow \text { thiocholine }+ \text { butyric acid }
\end{aligned}
$$

The above reactions occur in the absence of inhibitors. However, the addition of pesticides causes a significant decrease in the activity of these enzymes. As a consequence, there will be less or even no formation of the product thiocholine (TCh). The illustrative reaction scheme in biosensors based on AChE inhibition by carbamates or organophosphates (OPs) is presented in Equations 4 - 6 [25]:

$$
\begin{aligned}
& \mathrm{ATCh}+\mathrm{H} 2 \mathrm{O} \stackrel{\mathrm{AChE}}{\rightarrow} \text { thiocholine }+\mathrm{CH} 3 \mathrm{COOH} \\
& \text { thiocholine }+2 \mathrm{Co}-\mathrm{PC}(\mathrm{ox}) \rightarrow \text { thiocholine (oxidized form) }+2 \mathrm{Co}-\mathrm{PC}(\text { red }) \\
& \mathrm{Co}-\mathrm{PC}(\mathrm{red}) \rightarrow \text { Co-PC(ox) }+2 \mathrm{e}-
\end{aligned}
$$

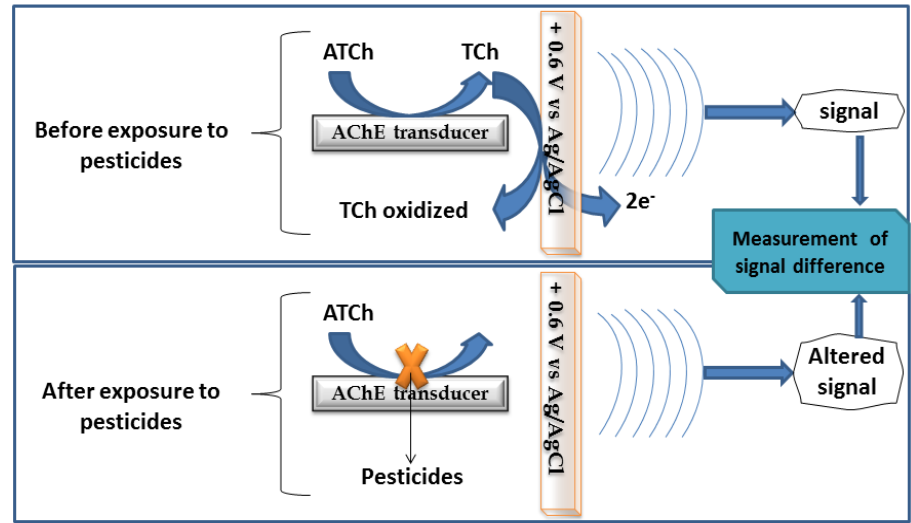

Figure 1. Amperometric determination of pesticides based on AChE inhibition 
The poor presence or even absence of TCh leads to a consequent decrease in the oxidation current that is measured to quantify the pesticides [21]. The challenge is that the oxidation of interfering electroactive species requires more potential and the peak of TCh oxidation is very weak, resulting in a relatively poor sensitivity [20], [21]. An efficient technique of minimizing the potential requirement for the oxidation of TCh is the use of nanomaterials, as they are characterized by efficient electron transfer ability [21], [26].

The principle is similar in cases where natural substrates $\mathrm{ACh}$ and $\mathrm{BCh}$ are used, as shown in Equations 7 and 8 [3]. The challenge in this case is related to the non-electrochemical behavior of the catalytic product choline. Therefore, the change in $\mathrm{pH}$ due to acid formation is measured for the evaluation of the inhibition level as shown in Figure 2.

$$
\begin{aligned}
& \text { acetylcholine }+\mathrm{H} 2 \mathrm{O} \rightarrow \text { chôhE }+ \text { acetic acid } \\
& \text { butyrylcholine }+\mathrm{H} 2 \mathrm{O} \rightarrow{ }^{\text {BCh }} \text { Chine }+ \text { butyric acid }
\end{aligned}
$$

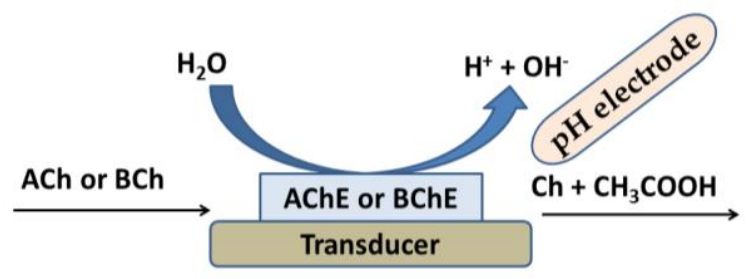

Figure 2. Potentiometric measurement of $\mathrm{pH}$ change

Potentiometric indicators with a $\mathrm{pH}$-sensitive glass electrode are generally involved in this type of measurement [26].

\subsubsection{Biosensor Based on Two-Enzyme Immobilization for Pesticides Detection}

The bi-enzymatic biosensors are usually constructed by associating a cholinesterase enzyme (ChE) to choline oxidase (ChOD), where ChOD is used to oxidize choline to hydrogen peroxide (H2O2) as shown in Equation 9 [20].

$$
\text { acetylcholine } \rightarrow \text { choline } \rightarrow \text { betain }+\mathrm{H} 2 \mathrm{O} 2
$$

Tyrosinase or alkaline phosphatase can also be associated to ChE enzymes for the construction of these types of biosensors. Andreescu et al. [32] immobilized AChE together with tyrosinase on a SPE, where the hydrolysis of phenyl acetate results in the formation of phenol compounds with high oxidation potential. The amperometric measurements in case of AChE and phenyl acetate as substrate, at potential between 100 $\mathrm{mV}$ and $-150 \mathrm{mV}$ against the $\mathrm{Ag} / \mathrm{AgCl}$ reference electrode displayed limits of detection of $5.2 \times 10^{-3} \mathrm{mg} \mathrm{L}-1$ and $0.56 \times 10^{-3} \mathrm{mg} \mathrm{L}-1$ respectively for inhibitors paraoxon and chlorpyrifos ethyl oxon.

The immobilization of Chlorella vulgaris microalgae was utilized for the construction of a bienzymatic conductometric biosensor for simultaneous detection of metal ions and pesticides. The presence of alkaline phosphatase allowed the detection of cadmium ion $(\mathrm{Cd} 2+)$, while paraoxon-methyl was successfully determined through the presence of AChE. The algae containing both enzymes was immobilized within a reticulated BSA membrane with GA vapors and deposited on an interdigitated conductometric electrode. As shown in Table 1, the LOD of the prepared biosensor was relatively low (10 ppb) for both $\mathrm{Cd} 2+$ and paraoxon-methyl, with a response time between 5-7 min [37]. 
Table 1. Comparison of Biosensors Based on Mono-, bi- and tri-enzyme Immobilization for Pesticide Detection

\begin{tabular}{|c|c|c|c|c|c|c|}
\hline References & Enzyme electrodes & Linear ranges & $\begin{array}{c}\text { Limit of } \\
\text { detections }\end{array}$ & Pesticide samples & $\begin{array}{c}\text { Food } \\
\text { samples }\end{array}$ & $\begin{array}{c}\text { Response } \\
\text { time }\end{array}$ \\
\hline $\begin{array}{c}\text { Cesarino et } \\
\text { al. }[27]\end{array}$ & $\begin{array}{l}\text { AChE/PANI/MWCNT/ } \\
\text { GCE }\end{array}$ & $\begin{array}{l}9.9 \text { to } 49.6 \mu \mathrm{mol} \mathrm{L}^{-1} \\
4.9-29.2 \mu \mathrm{mol} \mathrm{L}^{-1}\end{array}$ & $\begin{array}{l}1.4 \mu \mathrm{mol} \mathrm{L}^{-1} \\
0.95 \mu \mathrm{mol} \mathrm{L}^{-1}\end{array}$ & $\begin{array}{l}\text { carbaryl } \\
\text { methomyl }\end{array}$ & $\begin{array}{l}\text { apples } \\
\text { broccoli } \\
\text { cabbage }\end{array}$ & $10 \mathrm{~min}$ \\
\hline $\begin{array}{l}\text { Zhao et al. } \\
\quad[28]\end{array}$ & $\begin{array}{c}\mathrm{AChE} / \mathrm{MWNT}-\mathrm{SnO}_{2-} \\
\text { CHIT/Au }\end{array}$ & 2 to $500 \mu \mathrm{g} / \mathrm{L}$ & $2 \mu \mathrm{g} / \mathrm{L}$ & cholorpyrifos & $\begin{array}{l}\text { cucumbers } \\
\text { beans } \\
\text { spinach } \\
\text { cabbage } \\
\text { apples } \\
\text { tomatoes } \\
\text { lettuce }\end{array}$ & $10 \mathrm{~min}$ \\
\hline $\begin{array}{l}\text { Zhao et al. } \\
\quad[29]\end{array}$ & $\begin{array}{c}\text { AChE/PB- } \\
\text { CHIT/ERGO-AuNP- } \beta- \\
\text { CD/GCE }\end{array}$ & $\begin{array}{c}7.98-2 * 103 \mathrm{pg} / \mathrm{mL} \\
4.3-103 \mathrm{pg} / \mathrm{mL}\end{array}$ & $\begin{array}{l}4.14 \mathrm{pg} / \mathrm{mL} \\
1.15 \mathrm{pg} / \mathrm{mL}\end{array}$ & $\begin{array}{l}\text { Malathion } \\
\text { carbaryl }\end{array}$ & (1) & $10-20 \mathrm{sec}$ \\
\hline Bao et al. [1] & PLaE-CHIT/AuNP-GN & $\begin{array}{c}0.19-760 \mathrm{nM} \\
1.5-1513.5 \mathrm{nM}\end{array}$ & $\begin{array}{l}0.19 \mathrm{nM} \\
1.51 \mathrm{nM}\end{array}$ & $\begin{array}{l}\text { methyl parathion } \\
\text { malathion }\end{array}$ & $\begin{array}{l}\text { carrots } \\
\text { apples }\end{array}$ & $5-10 \mathrm{sec}$ \\
\hline $\begin{array}{l}\text { Lin et al. } \\
2004[30]\end{array}$ & $\mathrm{AChE} / \mathrm{ChO} / \mathrm{SPE}$ & 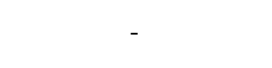 & $0.05 \mu \mathrm{M}$ & methyl parathion & - & - \\
\hline $\begin{array}{l}\text { Karousos et } \\
\text { al. [31] }\end{array}$ & QCM/AChE/ChO/HRP & - & $\begin{array}{l}3 \mathrm{ppm} \\
1 \mathrm{ppm}\end{array}$ & $\begin{array}{c}\text { carbaryl } \\
\text { dichlorvos }\end{array}$ & - & $30-45 \mathrm{sec}$ \\
\hline $\begin{array}{l}\text { Andreescu et } \\
\text { al. }[32]\end{array}$ & AChE/Tyr/SPE & $1 \times 10^{-5}-\underset{1}{2 \times 10^{-3}} \mathrm{~mol} \mathrm{~L}^{-}$ & $\begin{array}{c}5.2 \times 10^{-3} \mathrm{mg} \mathrm{L}^{-1} \\
0.56 \times 10^{-3} \mathrm{mg} \mathrm{L}^{-1}\end{array}$ & $\begin{array}{c}\text { paraoxon } \\
\text { chlorpyrifos ethyl } \\
\text { oxon }\end{array}$ & - & $2 \min$ \\
\hline $\begin{array}{l}\text { Bao et al. } \\
\quad[33]\end{array}$ & $\begin{array}{c}\text { ELP- } \\
\text { OPH/BSA/TiO }{ }_{2} \mathrm{NFs}_{\mathrm{O}} \mathrm{c}- \\
\mathrm{MWCNT}\end{array}$ & $\begin{array}{c}2-10 \mu \mathrm{M} \\
\text { Up to } 36.4 \mu \mathrm{M}\end{array}$ & 12 and $10 \mathrm{nM}$ & $\begin{array}{c}\text { parathion } \\
\text { methyl parathion }\end{array}$ & $\begin{array}{l}\text { spiked } 1 \\
\text { water }\end{array}$ & $5 \mathrm{sec}$ \\
\hline Yu et al. [34] & $\mathrm{AChE} / \mathrm{CNT}-\mathrm{NH}_{2} / \mathrm{GC}$ & $\begin{array}{c}0.2 \mathrm{nM} \text { to } 1 \mathrm{nM} \text { and } 1 \\
\mathrm{nM} \text { to } 30 \mathrm{nM}\end{array}$ & $0.08 \mathrm{nM}$ & paraoxon & $\begin{array}{l}\text { cabbage } \\
\text { celery, } \\
\text { onions, } \\
\text { carrots }\end{array}$ & $10 \mathrm{~min}$ \\
\hline Li et al. [35] & $\mathrm{AChE}-\mathrm{CdSe} / \mathrm{ZnS} / \mathrm{GR}$ & $10^{-12}-10^{-6} \mathrm{M}$ & $\begin{array}{l}10-14 \mathrm{M} \\
10-12 \mathrm{M}\end{array}$ & $\begin{array}{l}\text { paraoxon } \\
\text { dichlorvos }\end{array}$ & apple & $10 \mathrm{~min}$ \\
\hline $\begin{array}{l}\text { Zheng et al. } \\
\qquad[36]\end{array}$ & $\begin{array}{c}\text { GA/AChE-IL-GR- } \\
\text { Gel/GCE }\end{array}$ & $\begin{array}{c}10^{-14}-10^{-8} \mathrm{M} \\
10^{-13}-5.0 \times 10^{-8} \mathrm{M}\end{array}$ & $\begin{array}{l}5.3 \times 10^{-15} \mathrm{M} \\
4.6 \times 10^{-14} \mathrm{nM}\end{array}$ & $\begin{array}{c}\text { carbaryl } \\
\text { monocrotophos }\end{array}$ & tomato & $20 \mathrm{~min}$. \\
\hline $\begin{array}{l}\text { Chouteau et } \\
\text { al. [37] }\end{array}$ & Algae/BSA/GA & 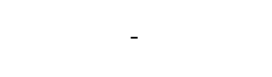 & $10 \mathrm{ppb}$ & $\begin{array}{c}\mathrm{Cd} 2+ \\
\text { paraoxon-methyl }\end{array}$ & water & 5-7 min. \\
\hline $\begin{array}{c}\text { Chen et al. } \\
\text { [38] }\end{array}$ & $\begin{array}{c}\mathrm{AChE} / \mathrm{MWCNT}-\mathrm{SnO}_{2-} \\
\mathrm{CHIT} / \mathrm{SPE}\end{array}$ & $0.05-1.0 \times 10^{3} \mu \mathrm{g} / \mathrm{L}$ & $0.05 \mu \mathrm{g} / \mathrm{L}$ & chlorpyrifos & $\begin{array}{l}\text { cabbage } \\
\text { lettuce } \\
\text { leeks, pak } \\
\text { choi } \\
\end{array}$ & $14 \mathrm{~min}$ \\
\hline
\end{tabular}

ERGO (electrochemically reduced graphene oxide); AuNPs (gold nanoparticles); $\beta$-CD ( $\beta$ cyclodextrin); PB (Prussian Blue); CHIT (Chitosan); GCE (glassy carbon electrode); SPE (screen-printed electrode), BSA (Bovine serum albumin), GA (gluteraldehyde); CdSe (Cadmium selenide dot); IL-GR (Ionic liquid functionalized graphene); Gel (Gelatin).

\subsubsection{Three-Enzyme Based Biosensor for Pesticides Detection}

Peroxidase is coupled to the bi-enzyme system to obtain a tri-enzymatic biosensors. As shown in Table 1, a three-enzyme immobilized system was used to construct a quartz crystal microbalance (QCM) sensor for the determination of organophosphorus and carbamate pesticides [31]. The reaction is shown in Equation 10.

$$
\text { acetylcholine } \stackrel{\text { AChE }}{\rightarrow} \text { choline } \stackrel{\text { ChOD }}{\rightarrow} \mathrm{H}_{2} \mathrm{O}_{2} \stackrel{\text { HRP }}{\rightarrow} \text { 3,3'-diaminobenzidine }
$$

Where 3,3'-diaminobenzidine is an insoluble product that precipitates out and adsorbs on the crystal surface, causing a decrease in the resonant frequency of the crystal. The QCM-enzyme sensor could detect carbaryl and dichlorvos concentrations up to $1 \mathrm{ppm}$.

\subsection{Other Inhibition-Based Pesticide Biosensors}

In addition to $\mathrm{ChE}$, a few other enzymes have been used for the development of inhibition basedbiosensors for the analysis of pesticides. For instance, plant esterase (PlaE) has been successfully used for the 
development of OP biosensor. The enzyme can be readily obtained from wheat, soybeans, rice, corn, and others. A cost-effective biosensor was developed based on the immobilization of plant esterase together with human chitotriosidase (CHIT), a member of the chitinase family on a gold nanoparticle-modified graphene nanosheet (PlaE-CHIT/AuNP-GN). The biosensor had a LOD of 0.19 and $1.51 \mathrm{mM}$ respectively for methyl parathion and malathion [1], as shown in Table 1. Wang et al. [8], reported that the inhibition method using purified esterase from wheat flour could detect different pesticides in samples of lettuce. The LOD were between 0.17 and $1.70 \mathrm{mg} / \mathrm{L}$. As the enzyme hydrolyzes the substrate $\alpha$-naphthyl acetate, it is referred to as $\alpha$-naphthyl acetate esterase (ANAE).

Acid and alkaline phosphatases can be used as biosensors based on an inhibition method for the detection of both carbamates and OPs. Electrochemical monitoring of Malathion and 2,4dichlorophenoxyacetic acid (2,4-D) was carried out based on the evaluation of the catalytic activity of alkaline phosphatase (ALP) in aqueous solution. A limit of detection between 0.5 and $6 \mu \mathrm{g} / \mathrm{L}$ was obtained only after 30 to $60 \mathrm{~min}$ of exposure [39]. Co-immobilization of acid phosphatase (AP) and glucose oxidase (GOD) has also been used for the fabrication of carbamate and OP biosensors. The LOD in this case depends on the type of pesticide to be analyzed. However, biosensors built on this technique are relatively more sensitive to organophosphorus compounds (with LODs as low as $1 \mu \mathrm{gL}^{-1}$ ) compared to carbamates [40]. Recent methods developed for OP detection include aptamers, molecularly imprinted polymers, biochips, nanobiosensors, and DNA-based and antibody-based immunosensors [2].

A one-step enzyme inhibition-based biosensor was proposed by Alonzo et al. [25] for the determination of three organophosphorus compounds in aqueous media. The rate of irreversible inactivation of the enzyme and the corresponding equilibrium constant obtained from the partial pressure were analyzed. A direct relationship was demonstrated between the enzymatic biosensors and the concentration of insecticides such as chlorpyrifos-oxon (CPO), chlorfenvinphos (CFV), and azinphos-methyl oxon (AZMO). An artificial neural network model was used to develop a biological transducer using AChE extracted from wild-type drosophila melanogaster and genetically modified microbe. The prediction capability and sensitivity of the model to low concentrations of the pesticides was determined with minimal errors after a set of 20 external test samples. The LODs were $1.479 \times 10^{-9}, 2.108 \times 10^{-7}$, and $2.016 \times 10^{-10} \mathrm{in} \mathrm{g} / \mathrm{L}$, respectively for CPO, CFV, and AZMO [23].

\subsection{Catalytic Biosensors}

This technique is based on the direct detection of OPs when a pesticide-specific enzyme is used to make the biosensor. In general, the enzymatic reaction results in the conversion of the substrate or analyte into products. The biosensor response is then quantified through the monitoring of either product formation or substrate consumption [14]. In the case of OPs detection, the technique relies primarily on the catalytic affinity of organophosphorus hydrolase (OPH) and organophosphorus acid anhydrolase (OPAA) for certain OPs.

OPs act as a substrate for OPH, which catalyzes the hydrolytic conversion of OPs into chromophoric and or electroactive products like p-nitrophenol or chlorferon. The cleavage of the P-O, P-F, P-S or P-CN bonds causes the release of protons that can be electrochemically measured [2], [4], [41]. The use of OPH, therefore, allows the development of potentiometric transducers like $\mathrm{pH}$ electrodes, FETs, or $\mathrm{pH}$ indicator dyes for the quantification of protons released, depending upon OP concentration. Immobilized OPH can also be used to develop amperometric transducers. The response in this latter case depends on the measurement of current resulting from the oxidation/reduction of the hydrolytic products [41]. The problem with OPH-based biosensors is that they usually show lower sensitivity values and higher LODs compared to that of cholinesterase-based biosensors. Moreover, the biosensors can be successfully used in the detection of only a few organophosphorus compounds, including parathion, methyl parathion, and paraoxon [20]. On the contrary, a metal ion-dependent enzyme (methyl parathion hydrolase from Pseudomonas sp. WBC-3) has shown considerable potential as enzyme-based biosensor owing to its specific catalytic property of hydrolysing methyl parathion, which is still widely used as pesticide [16].

OPAA is a type of dipeptidase that can effectively catalyze the hydrolysis of OPs with a P-F bond [16]. Thus, the enzyme can be used for specific and sensitive detection of diisopropylphosphorofluoridate and G-type OPs such as sarin (GB) and saman (GD) [14]. GB and GD are military designations respectively for nerve agents sarin and saman. An OPAA-based biosensor was developed by Simonian et al. (cited by [14]) for quantitative measurement of fluorine-containing sarin and soman. The hydrolysis of the P-F bond in fluorine-containing G-type OPs was specific, while other OPs did not respond.

\subsection{Recent Advances in the Development of Biosensors for Pesticide Detection}

The use of genetic engineering and nanotechnology is a key strategy that has emerged recently in order to improve the performance of enzyme-based biosensors for pesticide analysis. A desired enzyme can 
be genetically modified to increase its sensitivity and selectivity toward a targeted pesticide. Owing to their good electrochemical properties and biocompatibility, nanomaterials have been used as key elements to improve the sensitivity of biosensors [16].

\subsubsection{Genetic Engineering of the Biological Recognition Element}

Genetic engineering (e.g., site-directed mutagenesis at specific amino acids) has allowed the production of various recombinant enzymes (generally AChE) with high specificity and inhibition constants for pesticides. The enzymes are designed in such a way that pesticides can easily bind to their active sites [16].

Owing to the high inhibition sensitivity of AChE from Drosophila melanogaster (DmAChE) to OPs and carbamates, several studies have been undertaken for the production of recombinant DmAChE, and the immobilization of AChE for the detection of these pesticides [16]. A disposable screen-printed carbon electrode was developed for rapid detection of OPs and carbamates. The transducer consisting of immobilized DmAChE on MWCNTs with the help of Prussian blue allowed the detection of $0.5 \mu \mathrm{g} / \mathrm{L}$ of dichlorvos and carbofuran [42]. A cost effective biosensor was constructed with a genetically engineered $\mathrm{AChE}$ as an alternative to the high-cost commercial DmAChE. AChE from Saccharomyces cerevisiae (yeast) was cloned in order to express a genetically modified $\mathrm{AChE}$ with a structure similar to that of the commercial DmAChE. The sequence of interest was collected from a commercial DmAChE and introduced into the yeast expression vector $\mathrm{pYes-DEST52.} \mathrm{A} \mathrm{sequence} \mathrm{responsible} \mathrm{for} \mathrm{glucoamylase} \mathrm{secretion} \mathrm{was} \mathrm{used} \mathrm{to} \mathrm{replace} \mathrm{the}$ signal peptide sequence to induce the expression. After successful induction of the modified vector into the yeast, a recombinant DmAChE was expressed. The introduction of galactose allowed the formation of the recombinant enzyme DmAChE at the surface of the yeast. The engineered DmAChE was then submitted to inhibition for the detection of OPs and carbamates. It was reported by the authors that the synthesized recombinant $\mathrm{AChE}$ was more sensitive to carbaryl and carbofuran compared to natural AChE from different species as well as recombinant enzymes such as Schizaphis graminum AChE and P. papatasi AChE produced in different baculovirus-based insect cell expression systems. A cDNA sequence (001D) encoding a carboxylesterase from $\mathrm{H}$. armigera strain was engineered in order to obtain an active enzyme. Three fusion proteins with different solubility/affinity tags were heterologously expressed in E. coli. Although the results from HPLC assay of the purified fusion proteins were low, the hydrolase activity towards $\beta$-cypermethrin and fenvalerate was measurable, with specific activities between 0.13 and $0.67 \mu \mathrm{M}$ min-1. The recombinant enzyme showed stability up to $40^{\circ} \mathrm{C}$ at variable $\mathrm{pH}$ between 6.0 and 11.0 [43]. An unmodified singlestranded helper DNA probe 1 (HP1) and a quencher-fluorophore probe (QFP) were engineered together and used as a biosensor for the detection of pesticide in food. The biosensor had a LOD of $3.3 \mu \mathrm{g} L-1$ [8].

Other technologies are based on the development of aptamers and immunosensors for effective quantitation of pesticides. Immunosensors can be used in organic mixtures for the analysis of pesticide residues in hydrophobic matrices. Martini et al. [44] used a Clark electrode as transducer and peroxidase enzyme as marker for the detection of pesticide residues in olive oil. A linear response between $10 \mathrm{nM}$ and 5 $\mu \mathrm{M}$ was obtained from the sample.

Using competitive binding technology, a molecular beacon (MB) was cloned to a recombinant broad-specificity DNA aptamer in order to develop an OP biosensor. A measurable fluorescent signal could be produced from the binding of the MB to the aptamer, allowing the quantification of OPs [45]. Systematic evolution of ligands by exponential enrichment (SELEX) was used for the selection of aptamers, which were structurally modified and shortened to focus on the binding region of the target. This indicated that loops of the aptamer played different roles in the recognition of different chemicals. Choosing the best option, an approach based on an engineered aptamer was successfully applied in real sample detection of OPs. The LOD for phorate, profenofos, isocarbophos, and omethoate reached 19.2, 13.4, 17.2, and 23.4 nM, respectively [37]. Techniques based on enzyme-linked immunosorbent assay (ELISA) have also been implemented and directed toward the detection of pesticide residues [46].

\subsubsection{Use of Polymers and Nanomaterials}

Molecularly imprinted polymers (MIPs) as generic alternatives to antibodies and aptamers have been used to enhance the biosensor performance. The sensor application is expanded by allowing selected functional monomers to be self-assembled around a target analyte. The presence of micro-cavities on the resulting MIP structures reflects both the shape and chemical property of the target compound. The development of molecular templates on the MIP increases its reusability up to 30 times. During the last few years, attention has been given to fluorescence and mass-sensitive acoustic transducers. The most explored technique is based on the use of a quartz crystal microbalance (QCM) modified together with imprinted polymers [47]. Microarrays of quantum dots (QDs) were modified layer-by-layer (LbL) via AChE immobilization for the development of an enzyme inhibition-based biosensor. The resulting arrays showed 
good sensitivity toward OPs, allowing their successful detection in water and fruit samples. A linear range between 5 and $100 \mu \mathrm{g} / \mathrm{L}$ was observed for parathion and paraoxon. In addition, the biosensor had a low LOD of $10 \mu \mathrm{g} / \mathrm{L}[48]$.

Carbon-based nanomaterials, e.g. carbon nanotubes (CNTs) and graphene oxide (GO), and metal nanoparticles, e.g., AuNPs, zirconium oxide $(\mathrm{ZrO} 2)$, titanium oxide (TiO2), and cadmium sulfide nanoparticles (CdS), have been used as immobilization support for enzymes to improve biosensor performance. These nanomaterials have high electrical conductivity, high surface-to-volume ratio, high retention of biological activities, and good chemical and mechanical stability. Furthermore, the modification of glass carbon or metal electrodes and the use of binding agents as well as stabilizers like CHIT, nafion, GA, Prussian blue, or BSA, increase the stability of the transducer and its electron-transfer efficiency. As a result, the need for high potential for signal detection is considerably reduced. For instance, a transducer consisting of an AChE/Prussian blue (PB)-CHIT/ GCE resulted in a good electrocatalytic activity towards the oxidation of thiocholine. The oxidation potential of thiocholine decreased from $0.68 \mathrm{~V}$ to $0.32 \mathrm{~V}$ against saturated calomel as reference electrode. The sensitivity and selectivity of the biosensor were consequently improved [21].

Cesarino et al. [27] conducted study on biosensor based on the immobilization of AChE on a modified GCE with polyaniline (PANI) and multiwalled carbon nanotubes (MWCNTs). The AChE/MWCNT/PANI/GCE electrode could catalyze the oxidation of thiocholine at $+0.25 \mathrm{~V}$ against an $\mathrm{Ag} / \mathrm{AgCl}$ reference electrode, allowing the detection of carbamate pesticides in apple, broccoli, and cabbage samples. The LODs for carbaryl and methomyl were 1.4 and $0.95 \mu \mathrm{mol} \mathrm{L-1}$ respectively. Reproducibility and repeatability values of the biosensor were 2.6 and $3.2 \%$ respectively. Immobilization of AChE onto modified nanocomposites has been viewed as a powerful tool to increase the biosensor response in detection of pesticides in fruit and vegetable samples [28]. A 1:3 ratio of tin dioxide ( $\mathrm{SnO} 2)$ and MWCNT nanoparticles was obtained by dispersing them in a $0.2 \%$ solution of CHIT. A $2.5 \mu \mathrm{L}$ suspension of the MWCNT-SnO2CHIT composite was then used to modify the surface of a gold (Au) electrode. AChE was finally immobilized on the surface of the prepared AChE/MWCNT-SnO2-CHIT/Au electrode. The performance of the synthesized electrode toward the detection of cholorpyrifos in various fruit and vegetable samples is presented in Table 1. Furthermore, co-modification of nanomaterials results in nanocomposites with enhanced properties. For instance, composites like SnO2NPs/GO, AuNPs/MWCNTs, AuNPs/PB, $\mathrm{ZrO} 2 / \mathrm{CHIT}$ composite film, TiO2-decorated graphene, and CdS-decorated graphene have been successfully used to produce highly sensitive biosensors for pesticide detection [1]. Nanomaterials and hybrids therefore enable detection of pesticides down to picomole range, while enhancing stability of the biosensors [16].

Zhou and his collaborators [47] developed an OP biosensor through immobilization of AChE on GO, with the use of CHIT to enhance the covalent binding. GO-CS suspension was dropped onto a GCE prior to immobilization of AChE. The GO-CS enhanced the immobilization efficiency with an excellent biocompatibility and a good electrocatalytic perfomance to TCh oxidation. The biosensor could detect as low $1.2 \mathrm{nM}$ and $2.5 \mathrm{nM}$ respectively for trichlorfon, and carbaryl. Liu and Lin [48] developed a layer-by-layer (LbL) self-assembly of AChE and MWCNTs onto the surface of a GCE for detection of OPs. Another biosensor was developed through simultaneous immobilization of AChE together with alternating layers of polydiallyldimethylammonium chloride (PDDA) on the MWCNT. An alternate structure (PDDA/AChE/PDDA) was then obtained on the MWCNT electrode, allowing the enzyme to retain most of its bioactivity, resulting in a low limit of detection of $0.4 \mathrm{pM}$ for paraoxon after only 6 min of contact.

Colloidal gold has been one of the most applied metal nanoparticles in the technology of biosensor development. Like various other metals nanoparticles, AuNPs are attractive for construction of OP biosensors owing to their ability to load large amounts of enzyme on their surface and enhance its sensitivity toward Ops [1]. However, owing to the non-continuity of metal nanoparticles, further enhancement of their electrical conductivity is required to develop high-performance electrochemical biosensors. Graphene nanosheets (GNs) can be combined with metals owing to their excellent conductivity, mechanical properties, and high surface areas [1]. Based on the synergistic advantages of CHIT, AuNPs, and GNs, Bao et al. [1] proposed an ultrasensitive and selective biosensor for the detection of OPs. The CHIT/AuNP-GN hybrid nanocomposite allowed good electron transfer, thus enhancing the electrical conductivity of the biosensor while providing a favorable microenvironment for enzyme in OPs detection. A limit of detection of 0.19 and $1.51 \mathrm{mM}$ was obtained respectively for methyl parathion and malathion. Another technique consists of immobilizing the enzyme on SPEs by bio-encapsulation in a gel composite [49], [50]. 


\section{CONCLUSION}

Enzyme-based biosensors have gained significant interest for the detection of food and environmental pollutant. Thanks to their simplicity, portability, and low production cost. They require only a small amount of test sample and operate with high specificity and rapid response [51].

The use of enzyme biosensor in the determination of OPs and carbamates relies mainly on the specificity and sensitivity of the immobilized enzyme toward these compounds. The signal generated as a result of interaction between the enzyme and the substrate or the inhibitors is mostly electrochemical. Selectivity of the biosensors toward a target analyte (pesticides) is determined by the enzyme recognition layer, while the sensitivity is dependent on the transducer element. Polymer gels and nanomaterials have been widely used in the development of advanced biosensors, owing to their electrochemical properties as well as their biocompatibility.

Current challenges for practical applications of enzyme biosensors include the enzyme specificity toward a given pollutant and the relatively long exposure time required to get even a low signal at the electrode. Furthermore, there is a need to find ways to achieve higher sensitivity, wider linear range, and reusability of the biosensors. Considerable research is now being conducted to invent more effective techniques of constructing biosensors based on enzyme immobilization with improved performance. Pure, specifically improved enzymes and their efficient immobilization on nanomaterials are the key factors for the development of marketable biosensors for the detection of pesticides. Plant esterase has significant advantages over animal-derived choline esterases owing to its easy availability. Recent advances focus on the applications of novel nanomaterials in biosensor devices for enhancing the sensitivity and selectivity of the measurements. New avenues are being opened for development of biosensors for photosynthesis-inhibiting herbicides using immobilization of photosynthetic enzymes on different surfaces [52].

The authors of this review are currently investigating the extraction and characterization of alphanaphthyl acetate esterase from wheat flour and its successful immobilization on carbon-based nanomaterials like CNTs and graphene. The development of electrochemical biosensor based upon ANAE immobilization on MWCN and screen printed carbon electrode (SPE) for OPs detection is sought after. The enzymeinhibition kinetics in the presence of carbamates and OPs is also being studied. Results from this study could be useful for the development of cost-effective commercial biosensors for pesticide detection.

\section{ACKNOWLEDGEMENT}

The partial financial supports from the FRGS grant No. FRGS17-028-0594 (Ministry of Higher Education, Govt. of Malaysia) and RIGS grant No RIGS16-069-0233 (International Islamic University Malaysia) for editing work of this manuscript are gratefully acknowledged.

\section{REFERENCES}

[1]. Bao, J., Hou, C., Chen, M., Li, J., Huo, D., Yang, M., Lei, Y. Plant esterase-chitosan/gold nanoparticles-graphene nanosheet composite-based biosensor for the ultrasensitive detection of organophosphate pesticides. Journal of $\begin{array}{lllll}\text { Agricultural and } \quad \text { Food } & \text { Chemistry. }\end{array}$ http://pubs.acs.org/doi/abs/10.1021/acs.jafc.5b03971

[2]. Verma, N., Bhardwaj, A. Biosensor technology for pesticides: A review. Applied Biochemistry and Biotechnology. 2015; 175(6): 3093-3119. https://link.springer.com/article/10.1007/s12010-015-1489-2

[3]. Song, Y., Luo, Y., Zhu, C., Li, H., Du, D., Lin, Y. Recent advances in electrochemical biosensors based on graphene two-dimensional nanomaterials. Biosensors and Bioelectronics. 2016;76: 195-212. https://doi.org/10.1016/j.bios.2015.07.002

[4]. Gao, F., Lu, X. Detection of pesticides in foods by enzymatic biosensors. Improving and Tailoring Enzymes for Food Quality and Functionality. Ed. Rickey Yada, Elsevier, 2015; 147-160. http://dx.doi.org/10.1016/B978-178242-285-3.00007-7

[5]. Strelitz, J., Engel, L. S., Keifer, M.C. Blood acetylcholinesterase and butyrylcholinesterase as biomarkers of cholinesterase depression among pesticide handlers. Occup Environ Med. 2014; 71(12): 842-847. Doi:10.1136/oemed-2014-102315. http://oem.bmj.com/content/71/12/842.long

[6]. Rotariu, L., Lagarde, F., Jaffrezic-Renault, N., Bala, C. Electrochemical biosensors for fast detection of food contaminants - trends and perspective. TrAC Trends in Analytical Chemistry. 2016; 79 : 80-87. https://doi.org/10.1016/j.trac.2015.12.017

[7]. Van Dyk, J. S., Pletschke, B. Review on the use of enzymes for the detection of organochlorine, organophosphate and carbamate pesticides in the environment. Chemosphere. 2011; 82(3): 291-307. https://doi.org/10.1016/j.chemosphere.2010.10.033

[8]. Wang, J., Xia, Q., Zhang, A., Hu, X., Lin, C. Determination of organophosphorus pesticide residues in vegetables by an enzyme inhibition method using $\alpha$-naphthyl acetate esterase extracted from wheat flour. J. Zhejiang Univ. Sci. B. 2012; 13(4): 267-273. https://link.springer.com/article/10.1631/jzus.B11a0180 
[9]. Yang, L., Huo, D., Hou, C., He, K., Lv, F., Fa, H., Luo, X. Purification of plant-esterase in PEG1000/NaH2PO4 aqueous two-phase system by a two-step extraction. Process Biochemistry. 2010; 45(10): 1664-1671. https://doi.org/10.1016/j.procbio.2010.06.018

[10]. Monosik, R., Stredansky, M., Tkac, J., Sturdik, E. Application of enzyme Biosensors in analysis of food and beverages. Food Analytical Methods. 2011; 5(1): 40-53. https://link.springer.com/article/10.1007/s12161-0119222-4

[11]. Kumar, H., Neelam, R. Enzyme-based electrochemical biosensors for food safety: A review. Nanobiosensors in Disease Diagnosis. 2016; 29. https://doi.org/10.2147/NDD.S64847

[12]. Zhang, W., Asiri, A. M., Liu, D., Du, D., Lin, Y. Nanomaterial-based biosensors for environmental and biological monitoring of organophosphorus pesticides and nerve agents. TrAC - Trends in Analytical Chemistry. 2014; 54: 110. https://doi.org/10.1016/j.trac.2013.10.007

[13]. Upadhyay, L. S. B., Verma, N. Enzyme Inhibition Based Biosensors: A Review. Analytical Letters. 2013; 46(2): 225-241. http://dx.doi.org/10.1080/00032719.2012.713069

[14]. Songa, E.A., Okonkwo, J.O. Recent approaches to improving selectivity and sensitivity of enzyme-based biosensors for organophosphorus pesticides: A review. Talanta. 2016; 155: 289-304. https://doi.org/10.1016/j.talanta.2016.04.046

[15]. Dhull, V., Gahlaut, A., Dilbaghi, N., Hooda, V. Acetylcholinesterase biosensors for electrochemical detection of organophosphorus compounds: A review. Biochemistry Research International. 2013; 1-18. http://dx.doi.org/10.1155/2013/731501

[16]. Stoytcheva, M. Enzyme vs. bacterial electrochemical sensors for organophosphorus pesticides quantification. Intelligent and Biosensors. Vernon S. Somerset (Ed.). IntechOpen. 2010; DOI: 10.5772/7155. Available from: https://www.intechopen.com/books/intelligent-and-biosensors/enzyme-vs-bacterial-electrochemical-sensors-fororganophosphorus-pesticides-quantification

[17]. Wang, X., Hou, T., Dong, S., Liu, X., Li, F. Fluorescence biosensing strategy based on mercury ion-mediated DNA conformational switch and nicking enzyme-assisted cycling amplification for highly sensitive detection of carbamate pesticide. Biosensors and Bioelectronics. 2015; 77: 644-649. https://doi.org/10.1016/j.bios.2015.10.034

[18]. Sassolas, A. Biosensors for pesticidedetection: New trends. American Journal of Analytical Chemistry. 2012; 03(03): 210-232. doi:10.4236/ajac.2012.33030

[19]. Song, Y., Chen, J., Sun, M., Gong, C., Shen, Y., Song, Y., Wang, L. A simple electrochemical biosensor based on AuNPs/MPS/Au electrode sensing layer for monitoring carbamate pesticides in real samples. Journal of Hazardous Materials. 2015; 304:103-109. https://doi.org/10.1016/j.jhazmat.2015.10.058

[20]. Wei, M., Wang, J. A novel acetylcholinesterase biosensor based on ionic liquids-AuNPs-porous carbon composite matrix for detection of organophosphate pesticides. Sensors and Actuators, B: Chemical. 2015; 211: 290-296. https://doi.org/10.1016/j.snb.2015.01.112

[21]. Yan, J., Guan, H., Yu, J., Chi, D. Acetylcholinesterase biosensor based on assembly of multiwall carbon nanotubes onto liposome bioreactors for detection of organophosphates pesticides. Pesticide Biochemistry and Physiology. 2013; 105(3): 197-202. https://doi.org/10.1016/j.pestbp.2013.02.003

[22]. Prieto-Simón, B., Campàs, M., Andreescu, S., Marty, J.-L. Trends in flow-based biosensing systems for pesticide assessment. Sensors. 2006; 6(10):1161-1186. https://doi.org/10.3390/s6101161

[23]. Alonso, G. A., Istamboulie, G., Noguer, T., Marty, J. L., Muñoz, R. Rapid determination of pesticide mixtures using disposable biosensors based on genetically modified enzymes and artificial neural networks. Sensors and Actuators, B: Chemical. 2012; 164(1): 22-28. https://doi.org/10.1016/j.snb.2012.01.052

[24]. Dimcheva, N.D., Horozova, E.G. Electrochemical enzymatic biosensors based on metal micro-nanoparticlesmodified electrodes: A review. Chemical Papers. 2015; 69(1). https://doi.org/10.1515/chempap-2015-0011

[25]. Cesarino, I., Moraes, F.C., Lanza, M.R.V., Machado, S.A.S. Electrochemical detection of carbamate pesticides in fruit and vegetables with a biosensor based on acetylcholinesterase immobilised on a composite of polyanilinecarbon nanotubes. Food Chemistry. 2012; 135(3): 873-879. https://doi.org/10.1016/j.foodchem.2012.04.147

[26]. Zhao, G., Guo, Y., Sun, X., Wang, X. A System for Pesticide Residues Detection and Agricultural Products Traceability Based on Acetylcholinesterase Biosensor and Internet of Things. Int. J. Electrochem. Sci. 2015; 10:3387- 3399. http://www.electrochemsci.org/papers/vol10/100403387.pdf

[27]. Zhao, H., Ji, X., Wang, B., Wang, N., Li, X., Ni, R., Ren, J. An ultra-sensitive acetylcholinesterase biosensor based on reduced graphene oxide-Au nanoparticles- $\square$-cyclodextrin/Prussian blue-chitosan nanocomposites for organophosphorus pesticides detection. Biosensors and Bioelectronics. 2015; 65: 23-30. https://doi.org/10.1016/j.bios.2014.10.007

[28]. Lin, Y., Lu, F., Wana, J. A disposable carbon nanotube modified screen-printed biosensor for amperometric detection of organophosphorus pesticides and nerve agents. Electroanalysis. 2004; 16(12). http://dx.doi.org/10.1002/elan.200302933

[29]. Karousos, N. G., Aouabdi, S., Way, A. S., Reddy, S. M. Quartz crystal microbalance determination of organophosphorus and carbamate pesticides. Analytica Chimica Acta. 2002; 469(2):189-196. https://doi.org/10.1016/S0003-2670(02)00668-2

[30]. Andreescu, S., Avramescu, A., Bala, C., Magearu, V., Marty, J. Detection of organophosphorus insecticides with immobilized acetylcholinesterase - comparative study of two enzyme sensors. Analytical and Bioanalytical Chemistry. 2002; 374(1): 39-45. https://link.springer.com/article/10.1007/s00216-002-1442-4

[31]. Bao, J., Changjun, H., Qiuchen, D., Xiaoyu, M., Jun, C., Danqun, H., Mei, Y., Khaled, H., Abdel, G., Wilfred, C., $\mathrm{Yu}, \mathrm{L}$. ELP-OPH/BSA/TiO2 nanofibers/c-MWCNTs based biosensor for sensitive and selective determination of 
p-nitrophenyl substituted organophosphate pesticides in aqueous system. Biosensors and Bioelectronics. 2016; 85: 935-942. https://doi.org/10.1016/j.bios.2016.05.094

[32]. Yu, G., Wu, W., Zhao, Q., Wei, X., Lu, Q. Efficient immobilization of acetylcholinesterase onto amino functionalized carbon nanotubes for the fabrication of high sensitive organophosphorus pesticides biosensors. Biosensors and Bioelectronics. 2015; 68: 288-294. https://doi.org/10.1016/j.bios.2015.01.005

[33]. Li, X., Zheng, Z., Liu, X., Zhao, S., Liu, S. Nanostructured photoelectrochemical biosensor for highly sensitive detection of organophosphorus pesticides. Biosensors and Bioelectronics. 2015; 64:1-5. https://doi.org/10.1016/j.bios.2014.08.006

[34]. Zheng, Y., Liu, Z., Jing, Y., Li, J., Zhan, H. An acetylcholinesterase biosensor based on ionic liquid functionalized -gelatin-modified electrode for sensitive detection of pesticides. Sensors and Actuators B: Chemical. 2015; 210:389-39. https://doi.org/10.1016/j.snb.2015.01.003

[35]. Chouteau, C., Dzyadevych, S., Durrieu, C., Chovelon, J. A bi-enzymatic whole cell conductometric biosensor for heavy metal ions and pesticides detection in water samples. Biosensors and Bioelectronics. 2005; 21(2):273-281. https://doi.org/10.1016/j.bios.2004.09.032

[36]. Chen, D., Jiao, Y., Jia, H., Guo, Y., Sun, X., Wang, X., Xu, J. Acetylcholinesterase biosensor for chlorpyrifos detection based on multi-walled carbon nanotubes-SnO2-chitosan nanocomposite modified screen-printed $\begin{array}{lllllll}\text { electrode. } & \text { Int. } & \text { J. } & \text { Electrochem. } & \text { Sci. } & 2014 ; & 10:\end{array}$ http://www.electrochemsci.org/papers/vol10/101210491.pdf

[37]. Mazzei, F., Botrè, F., Montilla, S., Pilloton, R., Podesta, E., Botrè, C. Alkaline phosphatase inhibition based electrochemical sensors for the detection of pesticides. Journal of Electroanalytical Chemistry. 2004; 574(1): 95100. https://doi.org/10.1016/j.jelechem.2004.08.004

[38]. Mazzei, F., Botrè, F., Botrè, C. Acid phosphatase/glucose oxidase-based biosensors for the determination of pesticides. Analytica Chimica Acta. 1996; 336(1-3): 67-75. https://doi.org/10.1016/S0003-2670(96)00378-9

[39]. Mulchandani, A., Chen, W., Mulchandani, P., Wang, J., Rogers, K. R. Biosensors for direct determination of organophosphate pesticides. Biosensors and Bioelectronics. 2001; 16(4-5): 225-230. https://doi.org/10.1016/S09565663(01)00126-9

[40]. Tang, Z., Chen, H., Song, S., Fan, C., Zhang, D., Wu, A. Disposable screen-printed electrode coupled with recombinant Drosophila melanogaster acetylcholin-esterase and multiwalled carbon nanotubes for rapid detection of pesticides. Journal of AOAC International. 2011; 94(1): 307-312. https://www.ncbi.nlm.nih.gov/pubmed/21391508

[41]. Li, Y., Liu, J., Lu, M. et al. Bacterial expression and kinetic analysis of carboxylesterase 001D from Helicoverpa armigera. International Journal of Molecular Sciences. 2016; 17(4): 493. http://doi.org/10.3390/ijms17040493

[42]. Martini, E., Merola, G., Tomassetti, M., Campanella, L. Agent Orange herbicides, organophosphate and triazinic pesticides analysis in olive oil and industrial oil mill waste effluents using new organic phase immunosensors. Food Chemistry. 2015; 169: 358-365. https://doi.org/10.1016/j.foodchem.2014.07.137

[43]. Zhang, C., Wang, L., Tu, Z., Sun, X., He, Q., Lei, Z., Xu, C., Liu, Y., Zhang, X., Yang, J. and Liu, X. Organophosphorus pesticides detection using broad-specific single-stranded DNA based fluorescence polarization aptamer assay. Biosensors and Bioelectronics. 2014; 55: 216-219. https://doi.org/10.1016/j.bios.2013.12.020

[44]. Yan, X., Li, H., Yan, Y., Su, X. Developments in pesticide analysis by multi-analyte immunoassays: A review. Analytical Methods. 2014; 6(11): 3543. http://doi.org/10.1039/C3AY41946K

[45]. Zahedi, P., Ziaee, M., Abdouss, M., Farazin, A., Mizaikoff, B. Biomacromolecule template-based molecularly imprinted polymers with an emphasis on their synthesis strategies: a review. Polymers for Advanced Technologies. 2016. http://onlinelibrary.wiley.com/doi/10.1002/pat.3754

[46]. Luan, E., Zheng, Z., Li, X., Gu, H., Liu, S. Inkjet-assisted layer-by-layer printing of quantum dot/enzyme microarrays for highly sensitive detection of organophosphorus pesticides. Analytica Chimica Acta. 2016; 916: $77-$ 83. https://doi.org/10.1016/j.aca.2016.02.019

[47]. Zhou, Y., Tang, L., Zeng, G., Chen, J., Wang, J., Fan, C., Yang, G., Zhang, Y. and Xie, X. Amplified and selective detection of manganese peroxidase genes based on enzyme-scaffolded-gold nanoclusters and mesoporous carbon nitride. Biosensors and Bioelectronics. 2015; 65: 382-389. https://doi.org/10.1016/j.bios.2014.10.063

[48]. Liu, G., Lin Y. Biosensor based on self-assembling acetylcholinesterase on carbon nanotubes for flow injection/amperometric detection of organophosphate pesticides and nerve agents. Analytical Chemistry. 2006; 78 : 835-843. http://pubs.acs.org/doi/abs/10.1021/ac051559q

[49]. Ben Oujji, N., Bakas, I., Istambouli, G., Ait-Ichou, I., Ait-Addi, E., Rouillon, R. and Noguer, T. Sol-gel immobilization of acetylcholinesterase for the determination of organophosphate pesticides in olive oil with biosensors. Food Control. 2013; 30(2): 657-661. https://doi.org/10.1016/j.foodcont.2012.09.005

[50]. Kim, B., Lee, Y., Lee, K., Koh, W. G. Immobilization of enzymes within hydrogel micro- particles to create optical biosensors for the detection of organophosphorus compounds. Current Applied Physics. 2009; 9(4): 225-228. https://doi.org/10.1016/j.cap.2009.06.043

[51]. Rathee, K., Dhull, V., Dhull, R., Singh, S. Biosensors based on electrochemical lactate detection: A comprehensive review. Biochemistry and Biophysics Reports. 2016; 5: 35-54. https://doi.org/10.1016/j.bbrep.2015.11.010.

[52]. Bucur , B., Munteanu, F.-D, Marty, J.-L, Vasilescu, A. Advances in enzyme-based biosensors for pesticide detection. Biosensors. 2018; 8: 27. https://doi.org/10.3390/bios8020027 